Article

\title{
Coupled Effects of Moisture Content and Inherent Clay Minerals on the Cohesive Strength of Remodelled Coal
}

\author{
Hongwei Zhang ${ }^{1,2,+} \mathbb{1}$, Zhijun Wan ${ }^{1, *}$, Dan Ma ${ }^{3,+}$, Bo Zhang ${ }^{4}$ and Peng Zhou ${ }^{1}$ \\ 1 Key Laboratory of Deep Coal Resource Mining (CUMT), Ministry of Education of China, School of Mines, \\ China University of Mining \& Technology, Xuzhou 221116, China; cumtzhw@gmail.com (H.Z.); \\ pengzcumt@gmail.com (P.Z.) \\ 2 Department of Energy and Mineral Engineering, EMS Energy Institute, and G3 Center, The Pennsylvania \\ State University, University Park, PA 16802, USA \\ 3 School of Resources \& Safety Engineering, Central South University, Changsha 410083, China; \\ dan.ma@nottingham.ac.uk \\ 4 Changping Coal Mine, Jincheng Anthracite Mining Group, Jincheng 048000, China; BZhang90@outlook.com \\ * Correspondence: zhjwan@cumt.edu.cn \\ + These authors contributed equally to this work.
}

Received: 14 July 2017; Accepted: 17 August 2017; Published: 20 August 2017

\begin{abstract}
Injecting water into a coal seam to enhance the cohesive strength of coal and thus minimize and reduce the coal wall spalling risk must be considered in underground coal mining systems. In general, coal with low cohesive strength contains clay minerals which may affect the stability of coal by interacting with water. Therefore, the coupled effects of moisture content and inherent clay minerals on the physical properties (i.e., cohesive strength and internal friction angle) of coal samples should be addressed. In this paper, direct shear tests were conducted by remodelling the Yiluo coal with various moisture contents ranging from 6.6\% to 20.7\%. According to Mohr-Coulomb failure criterion, cohesive strength and internal friction angle of coal were obtained. Afterwards, effects of moisture content and clay minerals (i.e., Kaolinite, Smectite and Illite) on the cohesive strength of coal were analysed using X-ray diffraction (XRD) method. The results show that cohesive strength increases when the moisture content rises from $6.6 \%$ to $17.6 \%$, after which it decreases with increasing moisture content. This trend can be well illustrated by the relationship between typical water retention curve (WRC) and suction stress of soil. Therefore, a moisture content of $17.6 \%$ would be an optimal value to enhance the stability of the Yiluo coal seam.
\end{abstract}

Keywords: clay minerals; cohesive strength; direct shear test; internal friction angle; water retention curve (WRC)

\section{Introduction}

In underground coal mining systems, coal wall spalling, gas emissions, and unexpected roof falling are serious disasters increasing the economic cost and challenging the security of coal production, especially when the coal seam is soft and weak [1-3]. The stability of soft coal seam is difficult to control due to the relatively low mechanical properties. Generally, coal contains clay minerals, such as Kaolinite and Illite, which can weaken the stability of coal seam [4]. To enhance the strength of soft coal seam, increasing the moisture content of coal to a certain degree via hydraulic measures has been developed rapidly in recent years. For hard coal, an increase in moisture content can reduce the cohesive strength and increase the deformation of coal [5-7]. However, clay minerals in soft coal may, to a greater or lesser degree, affect the cohesive strength of coal by interacting with water [8]. 
Therefore, the coupled effects of moisture content and inherent clay minerals on the cohesive strength of soft coal should be addressed.

Many studies have described the effect of moisture content on physical properties of coals, in which direct shear tests and uniaxial and triaxial compression tests were conducted, and the recorded cohesive strength and internal friction angle were analysed. It was found that the cohesive strength decreases with increasing moisture content for hard coal [2,5-7], however, the internal friction angle was independent of moisture content [6]. By contrast, research related to soft coal is limited and results vary. Some studies indicated that the cohesive strength of soft coal can be enhanced by a certain amount of moisture content [9], while some revealed that the cohesive strength decreases with moisture content [10]. Wang et al. [9] suggested that the cohesive strength of coal may be enhanced via prompting the agglomeration and cementation of coal particles. However, the shortcoming of these studies is that the effect of inherent clay minerals was not taken into consideration.

Previous studies have investigated the relationship between water retention curve (WRC) for a particular type of soil and the properties of the unsaturated soil [11-14]. For example, the WRC (referring to the relationship between water content and suction) has been suggested for the prediction of shear strength properties of an unsaturated soil [11,15-17]. In a typical WRC, the suction decreases with increasing water content as a sigmoid function, indicating that water content would affect the suction of soil, thus affecting the suction stress. Since the soil-water characteristic curve (e.g., WRC) is used as the basis for the prediction of unsaturated soil parameters such as suction stress, permeability and shear strength [18-20], it may be reasonable to estimate the physical properties of remodelled coal.

In this study, direct shear tests were conducted to study the effect of moisture content on physical properties of the Yiluo coal. X-ray diffraction (XRD) measurement was employed to analyse the qualitative of clay minerals. This paper is organized as follows. Firstly, the methodology is introduced. Secondly, results of the cohesive strength and internal friction angle of the remodelled coal under variable moisture conditions were obtained according to Mohr-Coulomb failure criterion. Thirdly, the effect of intruding water on the inherent clay minerals was discussed by analysing the XDR results and WRC. Finally, several conclusions are drawn.

\section{Materials and Methods}

\subsection{Sample Description and Preparation}

Coal, taken from the in situ working face of the Yiluo coal mine (Henan, China) (Figure 1a-c), was employed for laboratory tests. According to the China National Standard (GB/T212-2008), the moisture content $(\mathrm{M})$, ash yield $(\mathrm{A})$, volatile matter $(\mathrm{V})$, fixed carbon $(\mathrm{FC})$, total sulfur $(\mathrm{S})$, and calorific value $(\mathrm{CV})$ of the raw coal were determined (Table 1). According to the China National Standard (GB 5751-86), it is a kind of bituminous coal with moderately high ash.

The coal, taken from the NO. 2 coal seam (Figure 1b,c), is extremely chipped and can be easily broken into fragments. Therefore, this coal is difficult to cut into cylinders or cubes for uniaxial or triaxial tests. Furthermore, to obtain the mechanical properties of coal under various levels of moisture content, numerous samples should be prepared and tested. Therefore, remodelling of coal specimens is a repeated method which would be helpful to explore the effect of moisture content on mechanical properties of soft coal.

The soft coal blocks were smashed and sieved to particles with size fraction smaller than $1.0 \mathrm{~mm}$ (Figure 1d). The coal particles were sufficiently mixed to ensure that the distribution of particle was uniform $[21,22]$. Then, the raw particles were mixed with a certain weight percentage of water according to Equation (1). Thus, the remodelled specimens with various moisture content conditions (i.e., $6.6 \%, 12.3 \%, 17.6 \%, 19.6 \%$ and $20.7 \%$ ) can be achieved (Table 2). Afterwards, the cylinder coal specimens ( $\phi 61.8 \mathrm{~mm} \times 40 \mathrm{~mm}$ ) were collected and compacted by employing sampling tools (Figure 1e,f). Figure $1 \mathrm{~g}$ presents the primary schematic of a remodelled coal sample. Finally, five groups 
of specimens (i.e., G-1 to G-5) were prepared and maintained in a vacuum dryer (Figure 1e). It should be noted that the original and saturated moisture contents of the coal are $6.6 \%$ and $20.7 \%$, respectively.

$$
m_{w}=\frac{m_{0}}{1+0.01 w_{0}} \times 0.01\left(w_{1}-w_{0}\right)
$$

where $m_{w}$ is the weight of water $(\mathrm{g}) ; m_{0}$ is the weight of natural coal particles $(\mathrm{g}) ; w_{0}$ is the original moisture content $(\%)$; and $w_{1}$ is the required moisture content $(\%)$.

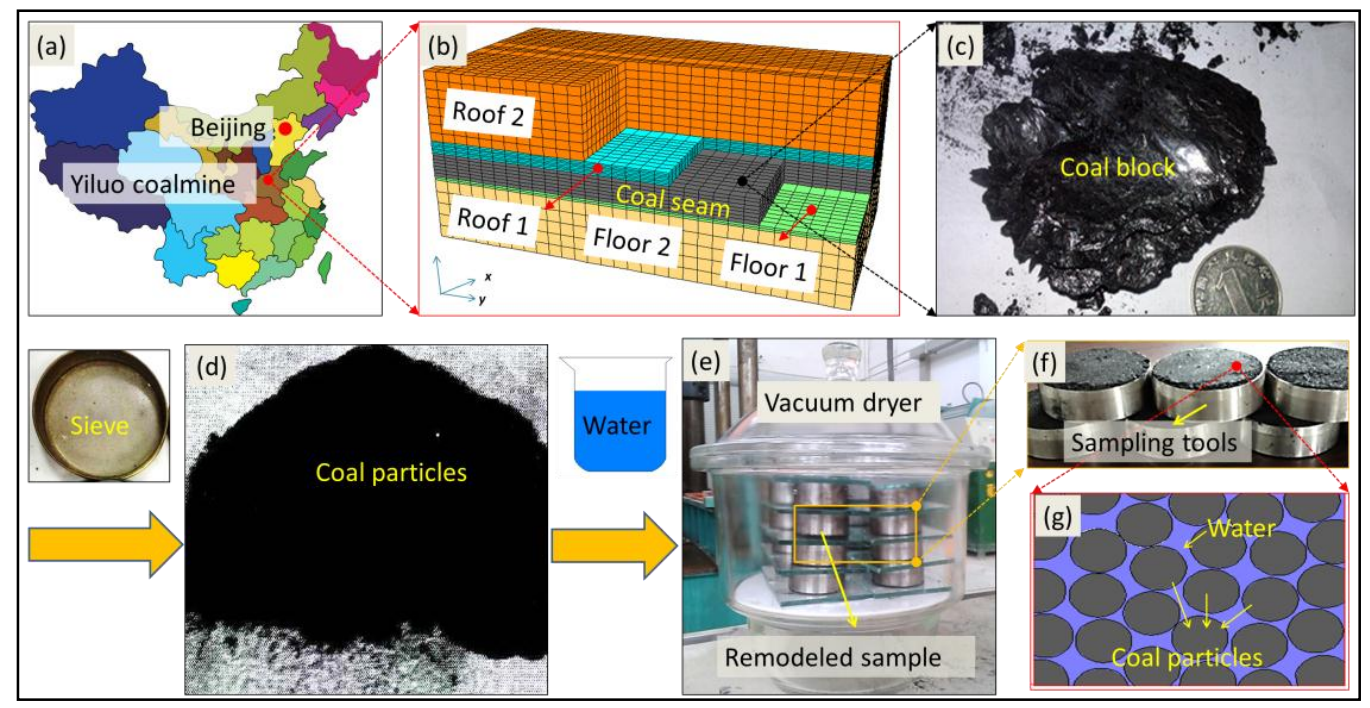

Figure 1. Remodelling processes. (a) Location of the Yiluo coalmine; (b) Three-dimensional schematic of a coal seam sandwiched between rock strata; (c) A coal block taken from the in situ Yiluo coal mine; (d) Coal particles; (e) Remodelled specimens in a vacuum dryer. (f) Remodelled specimens $(\phi 61.8 \mathrm{~mm} \times 40 \mathrm{~mm})$ in sampling tools; $(\mathrm{g})$ Schematic of water and coal particles.

Table 1. Proximate analysis of coal. W: water content; A: ash yield; V: volatile matter; FC: fixed carbon; S: total sulfur; CV: calorific value.

\begin{tabular}{ccccccc}
\hline Coal Seam & W (\%) & A (\%) & V (\%) & FC (\%) & S (\%) & CV (MJ/Kg) \\
\hline NO. 2 & 0.85 & 28.35 & 22.97 & 68.73 & 3.89 & 34.47 \\
\hline
\end{tabular}

Table 2. Physical properties of the remodelled samples and test conditions.

\begin{tabular}{ccccc}
\hline Group Number & Moisture Content (\%) & Density $\left(\mathbf{k g} / \mathbf{m}^{3}\right)$ & Normal Load $(\mathbf{k P a})$ & Shear Velocity $(\mathbf{m m} / \mathbf{m i n})$ \\
\hline G-1 & 6.6 & 1.30 & & \\
G-2 & 12.3 & 1.35 & & \\
G-3 & 17.6 & 1.45 & $100,200,300,400$ & \\
G-4 & 19.6 & 1.55 & & \\
G-5 & 20.7 & 1.65 & & \\
\hline
\end{tabular}

\subsection{Apparatus and Procedures}

\subsubsection{Direct Shear Test}

A series of unconsolidated undrained direct shear tests was conducted using the apparatus shown in Figure 2a-c. The direct shear test apparatus consists of a square box divided into two halves (Figure $2 \mathrm{~b}, \mathrm{c})$. The remodelled specimen $(\phi 61.8 \mathrm{~mm} \times 40 \mathrm{~mm}$ ), contained in the box, was subjected to a constant normal load, while an increasing horizontal force (i.e., shear force) was applied to the lower section of the shear box (Figure 2b,c). Specifically, displacement control method was employed and 
determined as $2.4 \mathrm{~mm} / \mathrm{min}$. Each specimen was tested three times to keep the accuracy. In these tests, the normal stresses were applied as $100 \mathrm{kPa}, 200 \mathrm{kPa}, 300 \mathrm{kPa}$ and $400 \mathrm{kPa}$ (Table 2).
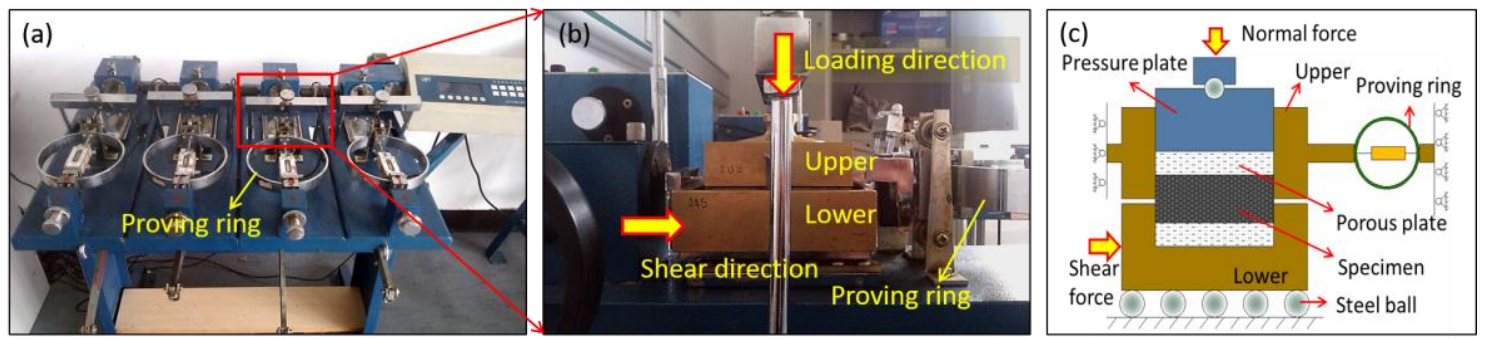

Figure 2. Test apparatus and methods. (a) Direct shear testing apparatus; (b) Shear vessel; (c) Schematic of the direct shear framework.

The tests were performed through the following procedures: (1) Placement of a specimen in the box; (2) Setting of a normal force to a specific load, such as $100 \mathrm{kPa}$; (3) Shearing the lower box at a constant displacement control rate until a steady peak shear strength appeared. During the entire shear experiment process, shear force and shear displacement were simultaneously recorded by a proving ring.

\subsubsection{X-ray Diffraction Observations}

The qualitative analysis of clay minerals was performed at the Advanced Analysis and Computation Center, China University of Mining and Technology, by XRD. The XRD tests using the D8 Advance powder diffraction machine can identify the presence of some clay materials. In the $\mathrm{XRD}$ test, radiation is $K$ in copper tube at $40 \mathrm{kV}$ and $30 \mathrm{~mA}$. Measurements were made at an exposing interval of $2 \theta\left(2^{\circ}-60^{\circ}\right)$, at a pitch of $2 \theta\left(0.01945^{\circ}\right)$ and with an exposing time of $0.1 \mathrm{~s}$ per pitch. The XRD tests were conducted at room temperature. Due to the limitation of the XRD system, the exact percentages of clay minerals cannot be measured. However, the relative magnitudes of the minerals can be identified.

\section{Results and Discussion}

\subsection{Direct Shear Test Results and Discussion}

\subsubsection{Shear Stress-Displacement Curves}

Direct shear tests under various constant normal stresses were performed for the remodelled specimens with variable moisture content conditions, i.e., $6.6 \%, 12.3 \%, 17.6 \%, 19.6 \%$ and $20.7 \%$. Normal force values of $100 \mathrm{kPa}, 200 \mathrm{kPa}, 300 \mathrm{kPa}$ and $400 \mathrm{kPa}$ were applied on specimens with a specific moisture content. Stress-displacement curves were obtained by plotting the shear stresses against the horizontal displacements (Figure 3a-e). It is clear that the trends and shapes of stress-displacement curves are similar to each other, and can be typically divided into three stages including elastic deformation stage, yield stage and stable shear stage (Figure 3a).

In the stress-displacement curves, the classical elasto-plastic responses of the remodelled coal are well captured, which were similar to the shear behaviours of normal consolidated clay and loose sand [23]. In Figure 3, there is a yield stage after the elastic deformation stage. In the yield stage, with the increment of the normal stress, the yield stage becomes more and more obvious. Moreover, the cementation between particles along the slip or shear plane will be damaged, and local cracking appears near the shear plane. After the yield stage, the mobilized shear stress increases to a peak value as roughness is mobilized and then keeps stable due to surface friction. The coal particles will continuously move and rotate under the action of the biting force or fiction [24]. The peak value defines the shear strength of the remodelled coal specimen, and a higher normal force implies a greater shear 
strength. However, the shear strengths of the remodelled specimens with various levels of moisture content are different, which will be analysed in the following sections.
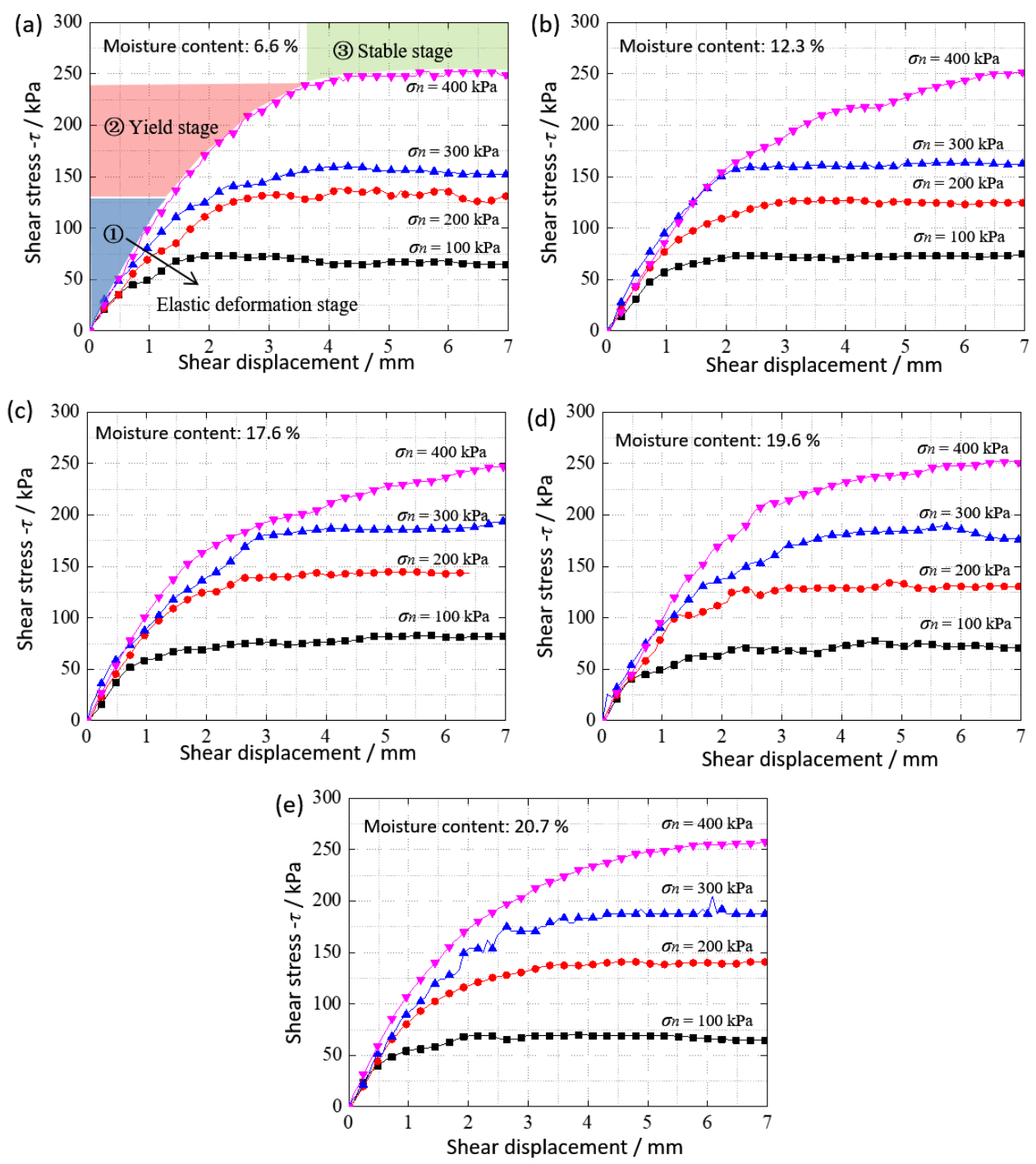

Figure 3. Typical stress-displacement curves under various normal stresses (i.e., $100 \mathrm{kPa}, 200 \mathrm{kPa}$, $300 \mathrm{kPa}$, and $400 \mathrm{kPa}$ ); (a) Moisture content is 6.6\%; (b) Moisture content is $12.3 \%$; (c) Moisture content is $17.6 \%$; (d) Moisture content is $19.6 \%$; (e) Moisture content is $20.7 \%$.

\subsubsection{Physical Properties Based on Mohr-Coulomb Failure Criterion}

\section{(1) Mohr-Coulomb Failure Criterion}

Shear failure of rocks is usually considered in geotechnical engineering, e.g., underground coal mining. According to the Mohr-Coulomb failure criterion, one of the most widely used strength criteria in geotechnical situations, failure is controlled by the basic properties of geomaterials including cohesive strength and internal friction angle.

Cohesive strength is the component of shear strength of a rock or soil that is independent of inter particle friction. Types of binding involved in cohesive strength include direct attraction of atoms in adjacent particles and attraction via the water between particles [25]. Internal friction angle represents the friction shear resistance of materials together with the normal stress, and can be influenced by various physical parameters, such as surface roughness, particle size and shape [26]. Moisture content is also an important factor that can affect the cohesive strength and internal friction angle. 
The basic concepts of the strength criterion suggest that the shear strength of a material is made up of two parts: constant cohesion and friction, varying with normal stress. As shown in Figure 4a, for a material under traditional triaxial stress state, with the increase of the maximum principle stress $\sigma_{1}$ and a constant confined pressure $\sigma_{3}$, shear failure may occur along a specific plane (i.e., plane a-b) that is subjected to normal stress $\sigma_{n}$ and shear stress $\tau$. The shear strength, $\tau$, was developed on this failure plane (Figure $4 \mathrm{~b}$ ) and is described as:

$$
\tau=\mathrm{c}+\sigma_{n} \tan (\varphi)
$$

where $c$ is the cohesive strength, $\sigma_{n}$ the normal stress acting on plane $\mathrm{a}-\mathrm{b}$, and $\varphi$ the internal friction angle. In the yield locus (Figure 4c), the cohesive strength and internal friction angle are described by the intercept and slope, respectively.

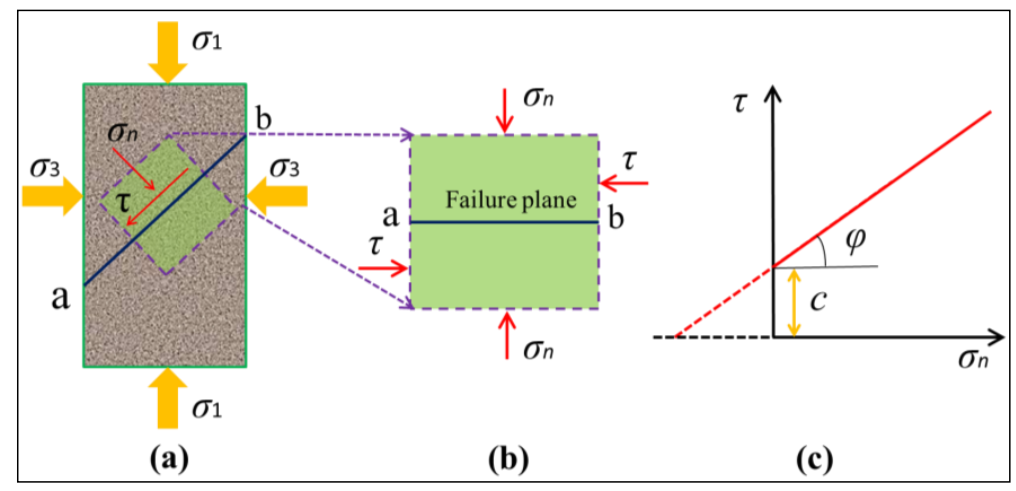

Figure 4. Mohr-Coulomb strength criterion. (a) Shear failure on plane $a-b$ under triaxial stress state and $\sigma_{3}$ is the confined pressure; (b) Shear failure under direct shear test; (c) Relationship between shear stress and normal stress.

(2) Fitting Results and Discussion

According to Equation (2), the cohesive strength and internal friction angle for the remodelled samples under variable moisture content conditions can be calculated by the slope and intercept of linear plots. Figure 5a-e present the linear fitted curves of the experimental data. As expected, shear stress increases linearly with normal stress, and all correlation coefficients are higher than 0.92 . Figure 6 shows the results of the cohesive strengths and internal friction angles under various moisture contents. It is clear that moisture content has a significant effect on the cohesive strength, while a small increase of $1.8^{\circ}$ can be identified in the internal friction angle versus moisture content curve.
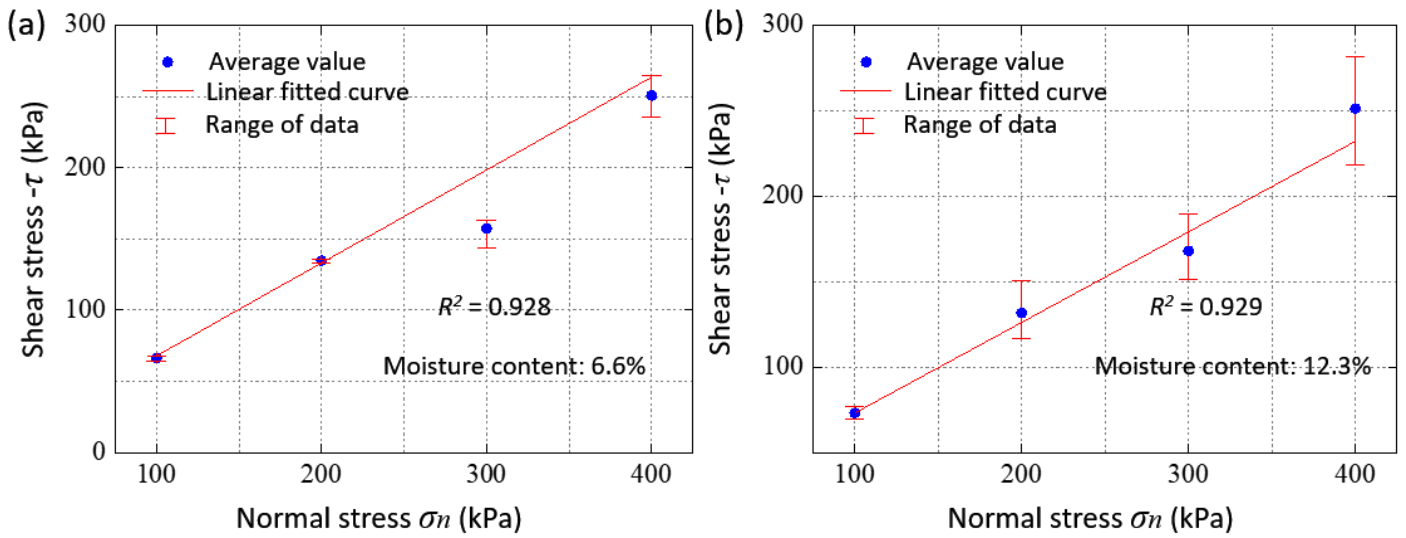

Figure 5. Cont. 

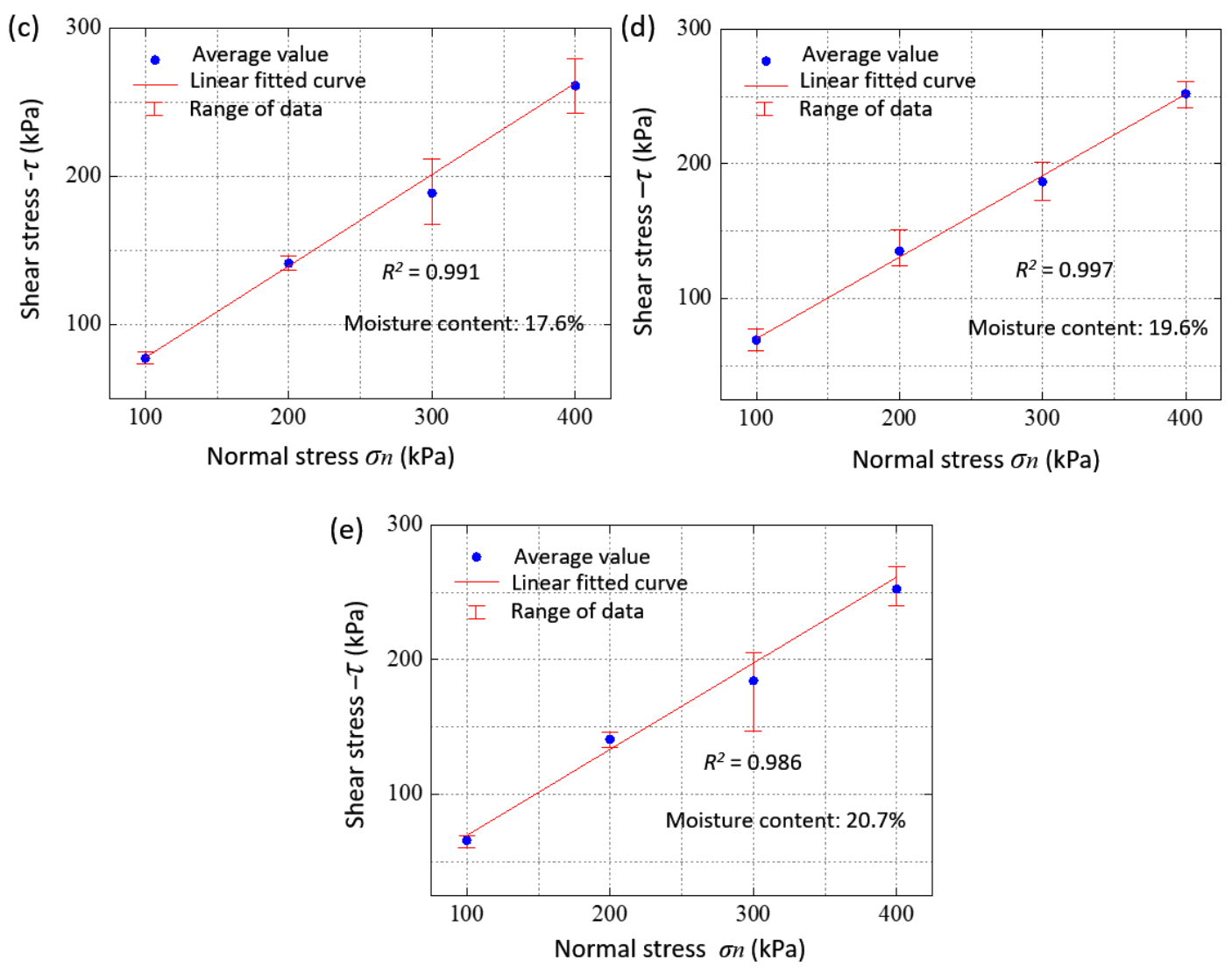

Figure 5. Linear regressive curves of the experimental data. (a) Moisture content is $6.6 \%$; (b) Moisture content is $12.3 \%$; (c) Moisture content is 17.6\%; (d) Moisture content is 19.6\%; (e) Moisture content is $20.7 \%$.

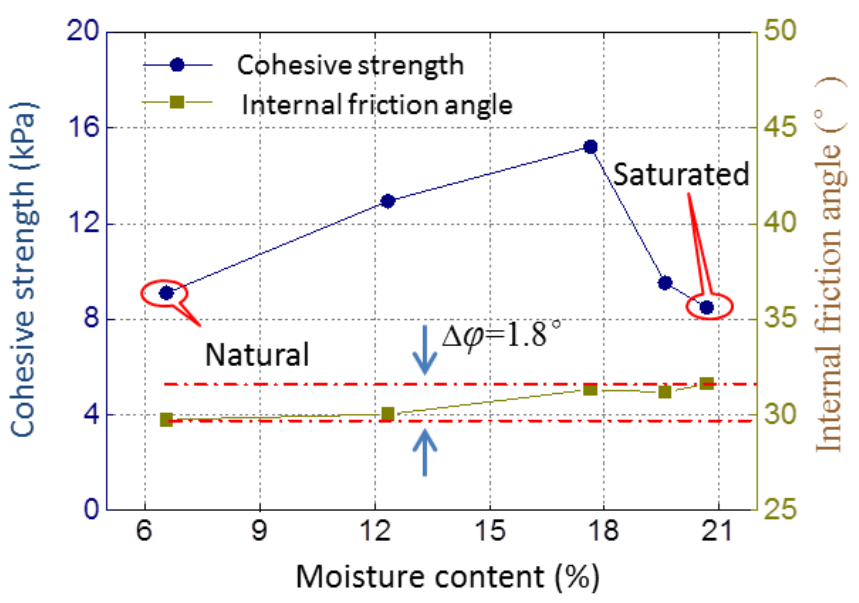

Figure 6. Effects of moisture content on cohesive strength and internal friction angle.

\section{- Cohesive Strength}

Figure 6 demonstrates that cohesive strength increases linearly form $9.1 \mathrm{kPa}$ to $15.2 \mathrm{kPa}$ with the moisture content raise from $6.6 \%$ to $17.6 \%$. However, after the peak, a sharp drop can be identified until the saturated point (a moisture content of $20.7 \%$ ). Specifically, the cohesive strength under the moisture-saturated condition is smaller than that under the original moisture content condition: $8.5 \mathrm{kPa}$ versus $9.1 \mathrm{kPa}$. The cohesive strength of the remodelled specimen should be lower than that of the naturally deposited coal, and this phenomenon is referred as sensitivity [23]. The shear strength 
is greatly reduced when materials are tested after remoulding without any change in the moisture content. The loss of strength of the Yiluo coal from remoulding is caused primarily by the destruction of the coal particle structure.

In previous studies (Table 3), the same effect of moisture content on cohesive strength can be found in various materials, such as coal, soil and clay. Wang et al. [9] indicated that water may enhance the cohesive strength of coal via bonding coal particles. After a threshold moisture content, water may weaken the strength by reducing the friction between adjacent particles. Similar to their study, Huang et al. [27] suggested that the strengthening effect is a result of the cementation of water. Thus, within a certain level of moisture content, water may act as 'cement', meanwhile, after a threshold value, water may act as 'lubricant'.

Table 3. References on the effect of moisture content on cohesive strength.

\begin{tabular}{cccc}
\hline References & Materials & Range of Moisture Content (\%) & Trend of Cohesive Strength \\
\hline Wang et al. [9] & Coal & $1.57-6.55$ & {$[1.57-3.07]$ increase; [3.07-6.55] decease } \\
Hu et al. [10] & Coal-bearing soil & $8.5-20.6$ & [8.5-20.6] decease \\
Cokca et al. [28] & Unsaturated clay & $18-28$ & {$[18-23]$ increase; [23-28] decease } \\
Consoli et al. [29] & Cemented soils & $4.0-13.5$ & {$[4.0-10]$ increase; [10-13.5] decease } \\
Liu and Zhu [30] & Mudstone & $10-20$ & {$[10-13]$ increase; [13-20] decease } \\
Huang et al. [27] & Soil & $3.0-27.5$ & {$[3.0-12.0]$ increase; [12.0-27.5] decease } \\
\hline
\end{tabular}

\section{- Internal Friction Angle}

Zou and Brusewitz [31] indicated that water may influence the internal friction angle by reducing the friction between particles. With more moisture, the film on the surface of a particle has a greater tendency to act as a lubricant. However, reports on coal [6,9], sandy loam soil [32] and other rocks [33-35] illustrated that small changes in the internal friction angle with moisture content can be identified. All values of the internal friction angle in this study are enclosed within a small range between $29.76^{\circ}$ and $31.63^{\circ}$ (Figure 6), showing a very small change. Generally, the internal friction angle is almost independent of moisture content when considering the experimental error. Therefore, a properly selected value of the internal friction from this range $\left(29.76^{\circ}-31.63^{\circ}\right)$ for moisture content would not affect the results of the numerical modelling or theoretical analysis advances in the future.

\subsection{Effect of Moisture Content on Inherent Clay Minerals}

Figure 7 presents the XRD results of naturally deposited coal, which indicates that minerals in the coal can be sorted by quantity as Kaolinite, Calcite, Smectite, Illite-Smectite mixture, Chlorite, Quartz, Siderite and other minerals in a descending order. Specially, Chlorite, Quartz, Siderite and other minerals can be neglected. Thus, the effect of water on clay minerals including Kaolinite, Smectite and an Illite-Semectite mixture will be analysed.

Table 4 shows the physiochemical properties of these materials. Kaolinite can be modelled and shaped with a certain amount of water, and the cohesive strength of Kaolinite particles can also be enhanced. Smectite is a type of clay mineral with strong water-absorption capability, which is always used as an addictive mineral to increase cohesive strength in geological situations. However, Illite can be easily broken in water, which, in turn, may reduce the cohesive strength of coal particles. The physicochemical properties displayed by these clays are the result of: (1) extremely small crystal size; (2) variations in internal chemical composition; (3) structural characteristics caused by chemical factors; (4) a large cation exchange surface area that is chemically active; (5) variations in types of exchangeable ions and surface charge; and (6) interactions with inorganic and organic liquids [36]. 


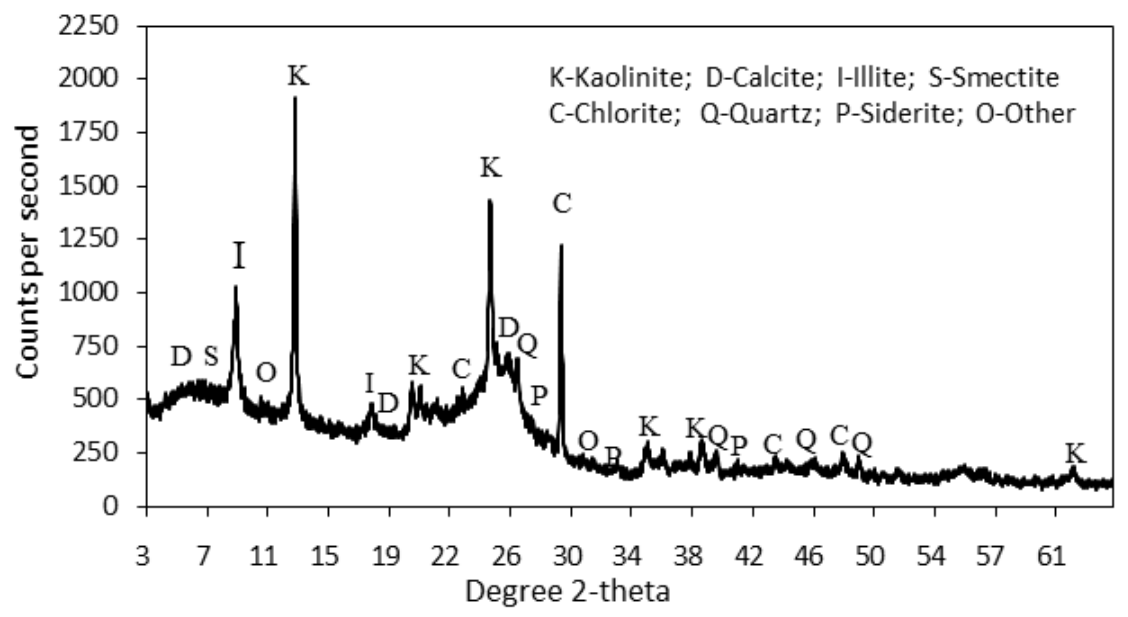

Figure 7. X-ray diffraction result of the Yiluo coal.

Table 4. Physicochemical properties of clay minerals.

\begin{tabular}{ccl}
\hline Minerals & \multicolumn{1}{c}{ Chemical Formula } & \multicolumn{1}{c}{ Introduction } \\
\hline Kaolinite & $\mathrm{Al}_{2} \mathrm{Si}_{2} \mathrm{O}_{5}(\mathrm{OH})_{4}$ & $\begin{array}{l}\text { Easily broken and can be moulded or shaped, especially when } \\
\text { wet. However, it does not expand when contacts with water. }\end{array}$ \\
\hline Smectite & $(\mathrm{Al}, \mathrm{Mg})_{2}\left[\mathrm{Si}_{4} \mathrm{O}_{10}\right](\mathrm{OH})_{2} \cdot \mathrm{nH}_{2} \mathrm{O}$ & $\begin{array}{l}\text { An absorbent clay that can absorb large quantities of water, } \\
\text { swelling to many times their original volume, and give rise to } \\
\text { permanent suspensions of gel-like masses. }\end{array}$ \\
\hline Illite & $\mathrm{K}_{0.75}\left(\mathrm{Al}_{1.75} \mathrm{R}\right)\left[\mathrm{Si}_{3.5} \mathrm{Al}_{0.5} \mathrm{O}_{10}\right](\mathrm{OH})_{2}$ & $\begin{array}{l}\text { A non-expanding clay and the capability of absorbing water is } \\
\text { weaker than that of Smectite. }\end{array}$ \\
\hline
\end{tabular}

The coupled effects of moisture content on the coal with low mechanical properties can be explained by some factors including cementation and lubrication. Firstly, the coal is made up of numerous coal particles and mineral particles. The clay minerals particles can be dissolved into the intruded water which in turn increase the absorbed suction of coal particles [37]. This common effect can be defined as cementation and is frequently employed to reduce fluid loss in drilling industry [36]. Secondly, the water-swellable minerals, such as Illite and Siderite, will change the microstructure of the matrix [38,39]. Thus may weaken the cohesive strength in a direct manner. Finally, with a large amount of water, the water film on the surface of a particle has a greater tendency to act as lubricant to decrease the cohesion of coal particles [9]. The following section discussed the effect of moisture content on the cohesive strength of coal particles based on the suction stress theory [19] for unsaturated soil.

\subsection{Discussion about the Sunction Stress and Cohesive Strength of Remodelled Coal}

The WRC represents the relationship between moisture content and suction in unsaturated materials, and the suction has a significant influence on the suction stress, and thus on the shear strength of geomaterials [16]. Generally, the WRC of soil has a ' $S$ ' shape (sigmoid curve) and several bimodal water retention curves have also been proposed in previous studies [16,18-20,40], which contribute to our knowledge about the water storage capability of soil.

Figure 8a shows the idealized WRC, which is a typical sigmoidal curve. According to the suction stress theory [19], the suction stress refers to the value of suction multiply the corresponding saturation content degree. Therefore, based on the idealized WRC in Figure 8a, suction stress can be calculated, which is shown as a dotted line in Figure 8a. In order to identify the relationship between saturation and suction stress, we plotted the suction stress versus degree of saturation content curve in Figure $8 b$. 
(a)

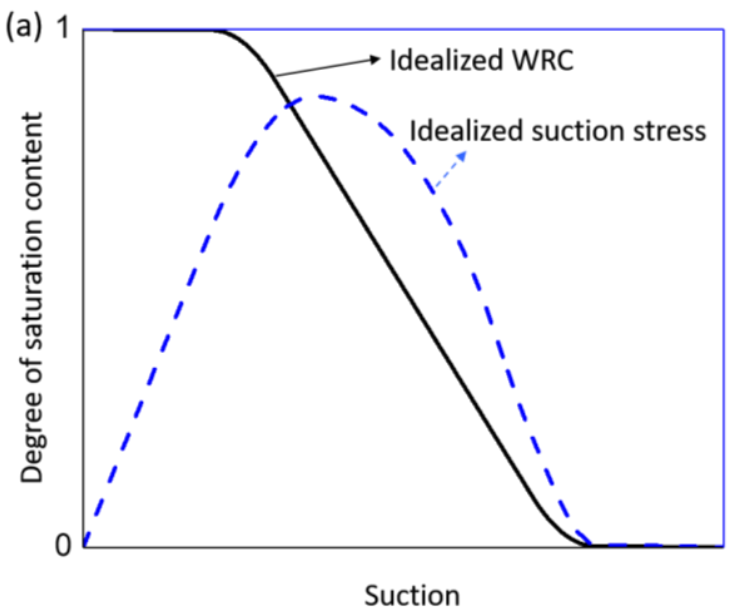

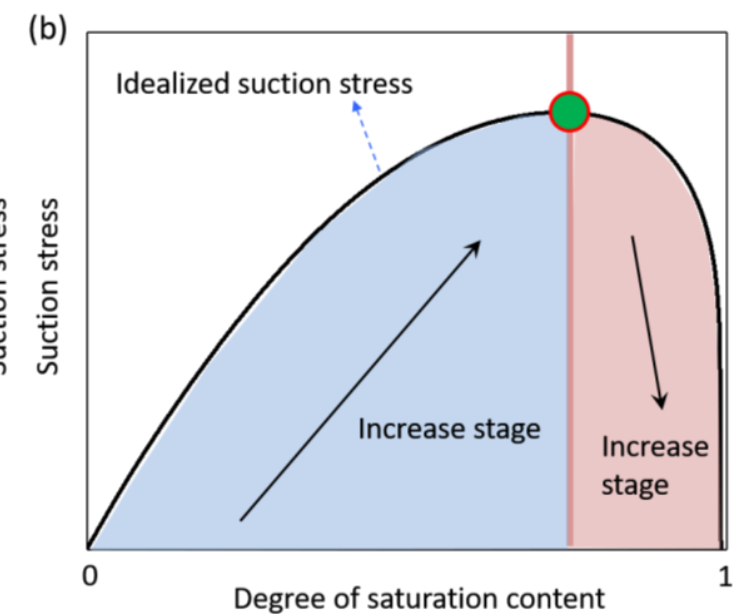

Figure 8. Idealized water retention curve (WRC) and suction stress. (a) Relationships between saturation and suction, and suction stress and suction; (b) Idealized suction stress and degree of saturation content, which is derived from (a).

In the suction stress and degree of saturation content curve that shown in Figure 8b, two typical stages can be seen. In the increase stage, the suction stress rises with increasing degree of saturation content, which means that the absorbing suction between particles increases with the growth of moisture content. Then, a peak suction stress is attained, indicating that the greatest absorbing suction stress between particles. However, as expected, the suction stress decreases with the increasing moisture content afterwards until a fully saturation state (e.g., degree of saturation content of 1.0) is reached. As mentioned in Section 3.1.2, the cohesive strength of remodelled coal increases from $9.1 \mathrm{kPa}$ to $15.2 \mathrm{kPa}$ with the moisture content rise from $6.6 \%$ to $17.6 \%$. After the peak, a sharp drop can be identified until a moisture content of $20.7 \%$ is reached. These results are consistent with the suction stress theory and the corresponding WRC that shown in Figure 8.

\section{Conclusions}

By remodelling the Yiluo coal specimens, direct shear tests were conducted to study the effect of moisture content on cohesive strength and internal friction angle of soft coal. Furthermore, the effect of clay minerals on the cohesive strength of the coal specimens was analysed using $\mathrm{X}$-ray diffraction (XRD) observation. The following significant conclusions can be drawn.

The cohesive strength of the coal saw an increase when the moisture content rises from $6.6 \%$ to $17.6 \%$, after which it decreases with moisture content. Besides, internal friction angle was found to be independent of moisture content. Thus, for the Yiluo coal, a moisture content of $17.6 \%$ would be the optimal value to enhance the stability of the coal seam.

Clay minerals including Kaolinite, Smectite and Illite play key roles in enhancing the cohesive strength of the coal. Firstly, within a certain moisture content (6.6-17.6\% in this study), the cementation of water with dissolved clay minerals can increase the absorbed suction of coal particles which in turn may enhance the cohesive strength of coal. Afterwards, when the moisture content reaches to a high level (above $17.6 \%$ in this study), the lubrication of water intends to decrease the cohesion of coal particles. In addition, according to the suction stress theory and corresponding typical WRC, the cohesive strength versus moisture content curve is consistent with the suction stress versus saturation curve.

Acknowledgments: This work was supported by the National Natural Science Foundation of China (No. 51674242). 
Author Contributions: Hongwei Zhang and Zhijun Wan conceived and designed the experiments; Hongwei Zhang, Bo Zhang and Peng Zhou performed the experiments; Hongwei Zhang and Dan Ma analyzed the data; Hongwei Zhang, Dan Ma, Yuan Zhang and Bo Zhang wrote the paper.

Conflicts of Interest: The authors declare no conflict of interest.

\section{References}

1. Molinda, G.; Mark, C. Ground failures in coal mines with weak roof. Electron. J. Geotech. Eng. 2010, 15, 547-588.

2. Shi, N.; Huang, Z. Application of longwall top coal caving in challenging geological conditions. In Proceedings of the World Congress on Mechanical, Chemical, and Material Engineering, Barcelona, Spain, 20-21 July 2015; p. 354.

3. Si, G.; Durucan, S.; Jamnikar, S.; Lazar, J.; Abraham, K.; Korre, A.; Shi, J.Q.; Zavšek, S.; Mutke, G.; Lurka, A. Seismic monitoring and analysis of excessive gas emissions in heterogeneous coal seams. Int. J. Coal Geol. 2015, 149, 41-54. [CrossRef]

4. Karimi, M. Mineral Impurities in Coal Combustion; Hemisphere Publishing Corp.: Carlsbad, CA, USA, 1985; pp. 141-181.

5. Kang, T.H.; Zhang, J.P.; Bai, S.W. Theoretical study and application of weakening top coal using water pre-infusion in fully mechanized sublevel caving mining. Chin. J. Rock Mech. Eng. 2004, 23, 2615-2621.

6. Lu, Y.; Zhou, Z.; Ge, Z.; Zhang, X.; Li, Q. Coupling effect of intruding water and inherent gas on coal strength based on the improved (mohr-coulomb) failure criterion. Minerals 2016, 6, 118. [CrossRef]

7. Pan, J.F.; Ning, Y.; Lan, H.; Peng, Y.W.; Xia, Y.X.; Wei, X.Z.; Wang, S.W. Water injection methods in coal bed based on experiments of water immersion time effect of qianqiu coal samples with burst trend. J. China Coal Soc. 2012, 37, 19-25.

8. Guo, B.B.; Chen, G.X. Experimental study on relationship between water content and shear strength parameters of soft rock in coal mine. Saf. Coal Mines 2013, 44, 4-7.

9. Wang, L.; Zhu, C.; Yin, Z.; Hou, J. Research on soft coal mechanics characteristic test for moisture content effect. J. Min. Saf. Eng. 2016, 33, 1145-1151.

10. Hu, X.; Hong, B.N.; Du, Q.; Meng, Y.M. Influence of water contents on shear strength of coal-bearing soil. Rock Soil Mech. 2009, 30, 2291-2294.

11. Fredlund, D.G.; Xing, A. Equations for the soil-water characteristic curve. Can. Geotech. J. 1994, 31, 521-532. [CrossRef]

12. Casini, F.; Serri, V.; Springman, S.M. Hydromechanical behaviour of a silty sand from a steep slope triggered by artificail rainfall: From unsaturated to saturated conditions. Can. Geotech. J. 2013, 50, 28-40. [CrossRef]

13. Casini, F.; Vassallo, R.; Mancuso, C.; Desideri, A. Application to a compacted soil of a cam clay model extended to unsaturated conditions. In Proceedings of the 1st European Conference on Unsaturated Soils. Advances in Geo-Engineering (E-UNSAT), Durham, UK, 2-4 July 2008; pp. 609-615.

14. Casini, F. Fundamentals of the hydromechanical behavior of multiphase granular materials. In New Frontiers in Oil and Gas Exploration; Springer International Publishing: Cham, Switzerland, 2016; pp. 461-486.

15. Fredlund, D.G.; Rahardjo, H. An Overview of Unsaturated Soil Behaviour; Geotechnical special publication, ASCE publishing: Dallas, TX, USA, 1993; pp. 1-31.

16. Casini, F.; Minder, P.; Springman, S.M. Shear Strength of An Unsaturated Silty Sand; Unsaturated Soils-Proceedings of the 5th International Conference on Unsaturated Soils: Barcelona, Spain, 2011; pp. 211-216.

17. D’Onza, F.; Gallipoli, D.; Wheeler, S.; Casini, F.; Vaunat, J.; Khalili, N.; Laloui, L.; Mancuso, C.; Mašín, D.; Nuth, M. Benchmark of constitutive models for unsaturated soils. Géotechnique 2011, 61, 283-302. [CrossRef]

18. Ciervo, F.; Casini, F.; Papa, M.N.; Rigon, R. Some remarks on bimodality effects of the hydraulic properties on shear strength of unsaturated soils. Vadose Zone J. 2015, 14, 1-12. [CrossRef]

19. Lu, N.; Likos, W.J. Suction stress characteristic curve for unsaturated soil. J. Geotech. Geoenviron. Eng. 2006, 132, 131-142. [CrossRef]

20. Casini, F. Consequences on water retention properties of double-porosity features in a compacted silt. Acta Geotech. 2012, 7, 139-150. [CrossRef] 
21. Ma, D.; Miao, X.X.; Wu, Y.; Bai, H.B.; Wang, J.G.; Rezania, M.; Huang, Y.H.; Qian, H.W. Seepage properties of crushed coal particles. J. Pet. Sci. Eng. 2016, 146, 297-307.

22. Ma, D.; Rezania, M.; Yu, H.S.; Bai, H.B. Variations of hydraulic properties of granular sandstones during water inrush: Effect of small particle migration. Eng. Geol. 2017, 217, 61-70. [CrossRef]

23. Helwany, S. Applied Soil Mechanics with Abaqus Applications; John Wiley \& Sons: Hoboken, NJ, USA, 2007.

24. Ma, D.; Li, Q.; Hall, M.; Wu, Y. Experimental investigation of stress rate and grain size on gas seepage characteristics of granular coal. Energies 2017, 10, 527. [CrossRef]

25. Kemper, W.D.; Rosenau, R.C. Soil cohesion as affected by time and water content. Soil Sci. Soc. Am. J. 1984, 48, 1001-1006. [CrossRef]

26. Moayed, R.Z.; Alibolandi, M.; Alizadeh, A. Specimen size effects on direct shear test of silty sands. Int. J. Geotech. Eng. 2017, 11, 198-205.

27. Huang, K.; Wan, J.W.; Chen, G.; Zeng, Y. Testing study of relationship between water content and shear strength of unsaturated soils. Rock Soil Mech. 2012, 23, 2600-2606.

28. Cokca, E.; Erol, O.; Armangil, F. Effects of compaction moisture content on the shear strength of an unsaturated clay. Geotech. Geol. Eng. 2004, 22, 285-297. [CrossRef]

29. Consoli, N.C.; Foppa, D.; Festugato, L.; Heineck, K.S. Key parameters for strength control of artificially cemented soils. J. Geotech. Geoenviron. Eng. 2007, 133, 197-205. [CrossRef]

30. Liu, Q.Y.; Zhu, Z.Q. Shear characteristics of siltized intercalation in red sandstone at different water contents. J. Shenyang Univ. Technol. 2012, 34, 220-235. [CrossRef] [PubMed]

31. Zou, Y.; Brusewitz, G.H. Angle of internal friction and cohesion of consolidated ground marigold petals. Trans. ASAE 2001, 44, 1255-1259.

32. Mouazen, A.M.; Ramon, H.; Jde, B. Effects of bulk density and moisture content on selected mechanical properties of sandy loam soil. Biosyst. Eng. 2002, 83, 217-224. [CrossRef]

33. Zhou, Z.; Cai, X.; Cao, W.; Li, X.; Xiong, C. Influence of water content on mechanical properties of rock in both saturation and drying processes. Rock Mech. Rock Eng. 2016, 49, 3009-3025. [CrossRef]

34. Zhou, Z.; Cai, X.; Chen, L.; Cao, W.; Zhao, Y.; Xiong, C. Influence of cyclic wetting and drying on physical and dynamic compressive properties of sandstone. Eng. Geol. 2017, 220, 1-12. [CrossRef]

35. Zhang, H.; Wan, Z.; Ma, D.; Zhang, Y.; Cheng, J.; Zhang, Q. Experimental investigation on the strength and failure behavior of coal and synthetic materials under plane-strain biaxial compression. Energies 2017, 10, 500. [CrossRef]

36. Odom, I.E. Smectite clay minerals: Properties and uses. Philos. Trans. R. Soc. Lond. 1984, 311, $391-409$. [CrossRef]

37. Polzer, W.L.; Hem, J.D. The dissolution of kaolinite. J. Geophys. Res. Atmos. 1965, 70, 6233-6240. [CrossRef]

38. Magaritz, M.; Luzier, J.E. Water-rock interactions and seawater-freshwater mixing effects in the coastal dunes aquifer, coos bay, oregon. Geochim. Cosmochim. Acta 1985, 49, 2515-2525. [CrossRef]

39. Whitney, G. Role of water in the smectite-to-illite reaction. Clays Clay Miner. 1990, 38, 343-350. [CrossRef]

40. Van Genuchten, M.T. A closed-form equation for predicting the hydraulic conductivity of unsaturated soils. Soil Sci. Soc. Am. J. 1980, 44, 892-898. [CrossRef]

(C) 2017 by the authors. Licensee MDPI, Basel, Switzerland. This article is an open access article distributed under the terms and conditions of the Creative Commons Attribution (CC BY) license (http://creativecommons.org/licenses/by/4.0/). 